\title{
The Role of Reading Automaticity and Prosody in Reading Comprehension of Elementary Students in Grades 2-4
}

\author{
Ji Yeon Lee ${ }^{\mathrm{a}}$, Young Tae Kim ${ }^{\mathrm{b}}$, Jin Kyung Kang ${ }^{\mathrm{b}}$ \\ "JungDam Speech, Language E Learning Clinic, Seoul, Korea \\ ${ }^{b}$ Department of Communication Disorders, Ewha Womans University, Seoul, Korea
}

\author{
Correspondence: Young Tae Kim, PhD \\ Department of Communication Disorders, Ewha \\ Womans University, 52 Ewhayeodae-gil, \\ Seodaemun-gu, Seoul 03760, Korea \\ Tel: $+82-2-3277-2120$ \\ Fax: +82-2-3277-2122 \\ E-mail: youngtae@ewha.ac.kr
}

Received: June 25, 2019

Revised: August 1, 2019

Accepted: August 20, 2019

This study was supported by the Ministry of Education of the Republic of Korea and the National Research Foundation of Korea (No. NRF2018S1A3A2075274).

\begin{abstract}
Objectives: Reading fluency has been traditionally assessed by reading automaticity (accuracy and speed), however recent studies have reported that prosody is another critical dimension. Previous studies found that reading fluency is strongly related to reading comprehension and the effect of reading fluency on reading comprehension is different depending on participants' school grade. The purpose of this study is to explore the relative contribution of reading automaticity and prosody to reading comprehension across grades. Methods: Seventy-six elementary school children (25 in the second grade, 24 in the third grade, and 27 in the fourth grade) participated in this study. All participants were tested to evaluate reading automaticity, reading prosody (attention to punctuation, inappropriate pause, declarative sentences $-F_{0}$ change, questions $-F_{0}$ change), vocabulary, reading comprehension. Stepwise multiple regressions were conducted to examine variables which can predict reading comprehension. Results: The variable which could predict reading comprehension was reading automaticity among the second and the third grades. In the fourth grade, however, the variables which could predict reading comprehension were vocabulary and inappropriate pauses. Conclusion: The results of this study suggest that predictive power of reading automaticity and prosody for reading comprehension may be different depending on participants'school grade and that it is necessary to assess both automatic and prosodic dimensions to measure the reading fluency of school-aged children.
\end{abstract}

Keywords: Reading fluency, Automaticity, Prosody, Reading comprehension
학령기에는 읽기가 학습의 도구이며 읽기능력이 전반적인 학습 에 영향을 미칠 수 있으므로 학령기의 읽기 발달은 매우 중요하다. 읽기의 궁극적인 목적은 읽기이해로 선행연구에서는 음운인식능 력, 낱말재인, 읽기 유창성 등의 해독능력과 어휘 및 구문지식 등의 언어능력이 읽기이해에 영향을 준다고 보고하고 있다(Hock \& Mellard, 2005).

언어능력 중 특히 어휘는 읽기이해와 관련이 높으며 읽기이해를 예측해 주는 중요한 변인으로 설명되고 있다(Kim \& Hwang, 2008; Muter, Hulme, Snowling, \& Stevenson, 2004; Nation, Adams, Bowyer-Crane, \& Snowling, 1999; Ouellette, 2006; Yoon, 2015). 어휘력 은 낱말을 확인하고 의미를 파악할 뿐 아니라 텍스트의 일차적 의
미를 파악하는 데 중요한 역할을 하며(Nippold, 2007) 어휘지식의 깊이가 깊을수록 텍스트 내의 개별 어휘를 활발하게 활성화하여 효과적인 읽기이해를 가능하게 한다(Yoon, Pae, \& Chung, 2018). Fuchs, Fuchs, Hosp와 Jenkins (2001)는 어휘력은 글을 빠르고 정 확하게 읽는 것과 유의한 상관이 있는데 이는 읽기이해에 영향을 준다고 하였다. Nation과 Snowling (1999)은 어휘집의 빠른 접근은 어휘의 표상, 조직화, 연결 등과 관련되는데 읽기이해는 결국 의미 적 표상을 세우는 능력이므로 어휘와 읽기이해는 깊은 관련성을 가진다고 해석하였다.

읽기 유창성은 과거에는 다른 읽기이해 요인에 비해 관심의 대상 이 아니었다(Lyon \& Moats, 1997). 하지만 낱말재인 능력 발달이 
반드시 읽기 유창성 향상으로 이어지는 것은 아니란 것이 밝혀지고 (Lyon \& Moats, 1997; Wolf \& Katzir-Cohen, 2001), National Reading Panel (2000)에서 성공적인 읽기를 위한주요 기술에 읽기 유창 성이 포함된다고 발표하면서 읽기 유창성의 중요성이 부각되었다.

읽기 유창성이란 빠르고 정확하게 자연스러운 표현력을 가지고 글을 읽을 수 있는 능력을 말하며 정확성(accuracy), 신속성(speed), 운율성(prosody) 측면에서 정의된다(National Reading Panel, 2000). 정확성은 낱말을 정확하게 해독하는 능력이며 신속성은 글을 빠르 게 자동적으로 읽는 능력이다(Kuhn \& Stahl, 2003). 운율성은 글 을 읽는 동안 끊어 읽기, 휴지, 억양, 음량 등을 적절히 사용하는 것 과 관련된다(Dowhower, 1991). Schreiber (1980)는 읽기 운율성을 소리의 강약이나 높낮이를 적절히 조절하면서 글자들을 유의미한 문법적 단위로 묶어 읽을 수 있는 능력이라고 정의했다.

읽기 유창성 평가는 형태 면에서 음독(oral reading fluency) 평 가와묵독(silent reading fluency) 평가로 나눌 수 있다. 묵독에서는 읽기 유창성 요인 중 신속성에 대한 평가만 가능하나 음독에서는 다른 요인들에 대해서도 평가가 가능하다(Fuchs et al., 2001).

읽기 유창성 평가의 수준은 낱말 수준과 텍스트 수준으로 나눌 수 있다. 텍스트 읽기 유창성이 낱말 읽기 유창성보다 읽기이해를 더 잘 예측한다고 보고하고 있어 읽기이해와 읽기 유창성의 관계를 살펴보는 연구에서는 텍스트 읽기 유창성으로 평가하는 경우가 많 다(Kim \& Wagner, 2015).

읽기 유창성 평가요인으로는 정확성, 신속성, 운율성이 있다. 정 확성과 신속성은 각 요인별로 평가하기 보다는 읽기 자동성(reading automaticity) 측면에서 단위시간 동안 정확하게 읽은 음절 또 는 어절수를 측정하여 함께 평가하는 것이 일반적이다(Kuhn \& Stahl, 2003). 읽기 자동성이란 인지적으로 많은 노력을 들이지 않 고 빠르고 정확하게 글을 읽을 수 있는 능력을 의미한다(LaBerge \& Samuels, 1974). 운율성에서는 문장을 구두점 또는 의미단위를 경계로 적절히 끊어 읽는지(Kuhn, Schwanenflugel, \& Meisinger, 2010; National Reading Panel, 2000), 평서문, 의문문 등의 문장유 형에 따라 적절한 음도변화를 주며 읽는지(Calet, Gutiérrez-Palma, \& Defior, 2015; Seo, 2016), 텍스트의 의미에 맞게 음량을 조절하며 읽는지(Zutell \& Rasinski, 1991)를 평가한다. 읽기 운율성 평가방법 에는 평가척도(rating scales)를 활용하는 방법과 스펙트로그램 (spectrogram)을 활용하는 방법이 있다. 평가척도 방법은 대상자 의 음독을 듣고 평가자가 음량, 끊어 읽기, 휴지, 강세, 억양 등에 대 해 평가척도를 활용하여 점수를 매기는 방법이다. 평가척도 방법은 평가 시간이 덜 소요된다는 장점이 있는 반면, 평가자의 주관이 반 영될 위험이 있고 읽기 속도와 정확성의 정도가 읽기 운율성 점수
에 영향을 미칠 수 있다는 단점이 있다(Schwanenflugel, Hamilton, Kuhn, Wisenbaker, \& Stahl, 2004). 스펙트로그램을 활용한 방법 은 스펙트로그램을 통해 운율성 하위요소인 끊어 읽기, 휴지, 억양 등을 평가하는 방법이다. 스펙트로그램은 문장산출 시 시간에 따 라 변하는 소리의 파형, 음도, 강도를 시각적으로 보여주며 객관적 인 수치를 제공하는 분석방법으로 스펙트로그램을 활용하면 운율 자질을 정확하고 객관적으로 측정할 수 있다(Schwanenflugel et al., 2004; Yang, 2003). 그 동안은 적절한 운율을 정의하는 것이 쉽 지 않고, 운율성은 정확성, 신속성과는 다르게 신뢰하게 평가하는 것이 어려워 읽기 유창성 평가 시 정확성과 신속성에 대해서만 평 가하고 읽기 자동성을 읽기 유창성과 동일한 의미로 확대해서 해 석하는 경우가 많았으나 최근에는 운율성도 읽기 유창성 평가의 중요한 요인으로 보고 있다(Kuhn et al., 2010; National Reading Panel, 2000).

읽기 유창성은 초등학교 전반에 걸쳐 발달하게 되는데 Chall (1983)의 읽기 발달 단계에 따르면 초등학교 읽기 발달은 세 단계로 나뉠 수 있다. 첫 번째 단계는 ‘문자 해독 단계’로 1,2학년이 이 시기 에 해당한다. 두 번째 단계는 '유창성 단계’로 2, 3학년이 이에 해당 한다. 이 단계에서는 문자해독 과정이 자동화 됨에 따라 해독의 정 확성이 높아지며 읽기 유창성이 발달한다. 세 번째 단계는 '의미 파 악을 위한 단계’로 초등학교 고학년 시기가 이에 해당한다. 이 단계 에 들어선 아동은 정확하고 빨라진 읽기능력을 바탕으로 인쇄된 문자 대신 자료의 내용에 보다 주의를 기울이게 되며 글의 의미에 초점을 두게 된다. 읽기 자동성은 저학년에 비해 고학년에서 유의 하게 높은 수행을 보이는 것으로 나타났다(Calet et al., 2015; Kim, Park, \& Kim, 2010; Kim \& Pae, 2012; Kuhn \& Stahl, 2003). 그러나 Fuchs 등(2001)은 읽기 자동성이 지속적인 발달 패턴을 보이는 것 은 아니라고 하며 읽기 자동성이 저학년 때는 가파른 상승을 보이 는 것에 비해 고학년 때는 수평에 가깝다고 하였다. 선행연구에서 는 읽기 자동성이 획득된 뒤에 자연스러운 표현력을 가지고 글을 읽기 시작하므로 읽기 운율성은 읽기 자동성이 발달되고 나면 나 타난다고 보았다(Kuhn \& Stahl, 2003; Miller \& Schwanenflugel, 2006; Schwanenflugel et al., 2004). 그러나 Cowie, Douglas-Cowie 와 Wichmann (2002)은 빠르고 정확하게 글을 읽을 수 있어도 운 율이 없는 경우가 있으므로 읽기 운율성과 자동성 발달은 어느 정 도 독립적이라고 하였다. Rasinski, Rikli와 Johnston (2009)도 자동 성이 획득되었다고 자연스럽게 운율성이 나타나는 것은 아니라고 보았다.

읽기 유창성이 읽기이해에 미치는 영향에 대한 두 가지 주요 접 근이 있다(Kuhn \& Stahl, 2003). 첫 번째 접근은 가장 잘 알려진 자 
동성 이론이다(LaBerge \& Samuels, 1974). 자동성 이론에 따르면 읽기란 여러 작업을 동시에 수행해야 하는 복잡한 인지 활동이기 때문에 비교적 정확하고 빠르게 글자를 해독할 수 있다면 글을 읽 는 동안 대부분의 인지적 자원을 읽은 자료를 통합하여 해석하는 읽기이해에 사용할 수 있다고 본다. 반면, 대부분의 인지적 자원을 글자 해독에 사용하게 되면 읽기이해에 사용할 인지적 자원이 없 게 되어 읽기이해에 실패하게 된다고 본다. 빠르고 정확하게 글을 읽을수록 높은 읽기이해를 보였다는 연구(Kim \& Wagner, 2015; Landerl \& Wimmer, 2008; Tilstra, McMaster, Van den Broek, Kendeou, \& Rapp, 2009)와 정확도와 속도를 높이는 읽기 유창성 중재 를 실시하였더니 읽기 유창성뿐 아니라 읽기이해도 향상되었다는 중재 연구(Lee \& Kim, 2009; Stahl \& Heubach, 2005)가 자동성 이 론을 뒷받침하고 있다. 반면, 정확도와 속도를 높이는 읽기 유창성 중재를 실시한 일부 연구에서는 자동성 측면에서의 읽기 유창성 향상이 반드시 읽기이해 향상을 이끌어내는 것은 아닌 것으로 나 타났다(Kuhn \& Stahl, 2003; Wexler, Vaughn, Edmonds, \& Reutebuch, 2008).

두 번째 접근은 읽기이해에 읽기 운율성이 기여한다는 접근이다. Kuhn과 Stahl (2003)에 따르면 독자는 글을 읽을 때 일단 낱말을 자동적으로 해독한 뒤 통사적으로 적절한 단위로 묶으며 글의 의 미를 이해한다. 이러한 과정에서 끊어 읽기, 휴지, 억양 등과 같은 운율적 요인들은 낱말을 유의미한 단위로 묶는데 필요한 통사적 정보를 제공해주기 때문에 읽기 운율성이 읽기이해에 영향을 준다 고 본다(McKenna \& Stahl, 2003). 운율성 측면에서 유창하게 글을 읽을수록 높은 읽기이해를 보였다는 연구(Miller \& Schwanenflugel, 2006; Rasinski et al., 2009; Ravid \& Mashraki, 2007; Valencia et al., 2010)와 읽기 운율성이 읽기이해를 설명할 수 있음을 확인한 연구(Arcand et al., 2014; Benjamin \& Schwanenflugel, 2010; Calet et al., 2015; Miller \& Schwanenflugel, 2008; Veenendaal, Groen, \& Verhoeven, 2015), 운율성 측면의 읽기 유창성 중재를 통해 읽기이 해가 향상됨을 보고한 연구(Calet, Gutiérrez-Palma, \& Defior, 2017; Jeong, 2007; Kim, 2011; Song, 2012; Young, Mohr, \& Rasinski, 2015) 가 운율성 이론을 뒷받침해주고 있다.

Calet 등(2015)은 읽기 자동성이 발달하고 있는 학령기 초기에 는 읽기 자동성이 읽기이해에 보다 중요한 역할을 할 수 있고, 이미 자동성을 획득한 학년에서는 자동성 보다 운율성이 읽기이해에 중 요한 역할을 할 수 있다고 보았다. 반면, Pressley 등(2009)과 Kuhn 등(2010)은 학령기 초기의 아동이 글을 소리 내어 읽는 것은 익숙 하지 않은 문어와 익숙한 구어가 연결되도록 해주고, 이 시기의 아 동은 자신이 읽은 것을 듣고 구어체 이해 기술을 적용하여 글의 내
용을 이해하므로 학령기 초기에 읽기 운율성이 읽기이해에 중요한 역할을 한다고 보았다. 따라서 읽기이해에 중요한 역할을 하는 읽 기 유창성 요인이 학년에 따라 다른지 확인할 필요가 있을 것이다.

읽기 자동성과 운율성이 읽기이해에 미치는 영향에 있어 학년에 따른 차이를 알아본 연구들이 외국 문헌을 중심으로 일부 이루어 졌다. Valencia 등(2010)은 영어가 모국어인 초등학교 2, 4, 6학년을 대상으로 읽기 자동성, 읽기 운율성, 읽기이해의 관계를 조사하였 는데 학년이 올라감에 따라 읽기 운율성의 읽기이해에 대한 기여 는 증가하는 반면 4 학년 이후에는 읽기 자동성의 읽기이해에 대한 기여가 감소하는 것을 발견했다. Calet 등(2015)은 스페인어가 모국 어인 초등학교 2,4 학년을 대상으로 글자 해독의 자동성을 통제했 을 때 읽기 운율성이 읽기이해에 얼마나 기여하는지를 알아보았는 데 읽기 운율성의 읽기이해에 대한 설명력이 2 학년 보다 4 학년에서 더 높게 나타났다. 읽기이해와 읽기 유창성과의 관계는 철자체계의 깊이(orthographic depth)에 따라 그 정도가 다른 경향이 있으며 (Landerl \& Wimmer, 2008), 아직 이와 관련된 국내 연구는 부족한 실정이다. 따라서 학년에 따라 읽기 자동성과 운율성이 읽기이해에 미치는 차이가 한글의 경우는 어떠한지 확인할 필요가 있을 것이다. 따라서 본 연구에서는 초등학교 2-4학년 일반아동을 대상으로 읽기 자동성과 읽기 운율성 평가를 실시하여 학년 간 수행력 차이 를 확인하고, 학년에 따라 읽기 자동성과 운율성이 읽기이해에 미 치는 영향에 있어 차이가 있는지를 살펴보았다.

\section{연구방법}

\section{연구대상}

본 연구는 서울 및 경기 지역의 초등학교 2-4학년 일반아동 76명 을 대상으로 하였다. 학년별로 2학년 25명, 3학년 24명, 4학년 27명 이 연구에 참여하였다. 연구 대상자 선정기준은 (1) 부모와 학급 담 임교사로부터 시청각의 감각, 인지, 정서 및 행동, 운동발달의 문제 가 없다고 보고된 아동, (2) 수용 - 표현어휘력검사(Receptive \& Expressive Vocabulary Test, REVT; Kim, Hong, Kim, Jang, \& Lee, 2009)의 수용어휘력 검사 결과 -1 SD 이상인 아동, (3) 한국어 읽기 검사(Korea Language-based Reading Assessment, KOLRA; Pae, Kim, Yoon, \& Jang, 2015) 상세검사 내 해독영역 표준점수가 91점 이상인 아동이다. 학년별 남녀 학생수, 어휘 및 해독 수행력에 관한 기술통계 결과는 Table 1에 제시하였다.

\section{연구도구}

읽기 자동성 검사는 읽기 성취 및 읽기 인지처리능력검사(Read- 
Table 1. Participants' characteristics

\begin{tabular}{|c|c|c|c|}
\hline & Grade $2(\mathrm{~N}=25)$ & Grade $3(\mathrm{~N}=24)$ & Grade $4(\mathrm{~N}=27)$ \\
\hline \multicolumn{4}{|l|}{ Gender } \\
\hline Male & 12 & 13 & 12 \\
\hline Female & 13 & 11 & 15 \\
\hline REVT_R (raw score) & $94.20(12.13)$ & $105.83(8.82)$ & $123.11(14.73)$ \\
\hline KOLRA_decoding (raw scorre) & $71.80(4.98)$ & $73.50(5.19)$ & $76.44(1.99)$ \\
\hline
\end{tabular}

Values are presented as mean (SD).

REVT_R: receptive test of Receptive \& Expressive Vocabulary Test (Kim, Hong, Kim, Jang, \& Lee, 2009); KOLRA_decoding: word decoding test of Korean Languagebased Reading Assessment (Pae, Kim, Yoon, \& Jang, 2015).

ing Achievement and Reading Cognitive Processes Ability, RARCP; Kim, Kim, Hwang, \& Yoo, 2014)의 읽기 유창성 검사를 사용 하였다. 검사 시 제시된 지문은 2 학년은 사또 엉덩이에 불나겠네(이 야기글)'와 ‘질경이(설명글)', 3학년은 ‘돼지가 꿀꿀하고 우는 이유 (이야기글)'와 ‘씀바귀(설명글)', 4 학년은 ‘청개구리 점쟁이(이야기 글)'와 '엉겅퀴(설명글)' 지문이었다. 각 글(이야기글, 설명글)에서 아동이 1 분 동안 읽은 '총 어절수'에서 '틀리게 읽은 어절수'를 빼서 원점수를 산출한 뒤, 이야기글과 설명글의 원점수의 합을 읽기 자 동성 점수로 기록하였다. 음독 중 대치, 첨가, 생략, 반복을 보인 경 우는 오답 처리하였고, 3 초 안에 자기 교정을 한 경우에는 정답 처 리하였다. 읽기 자동성 검사 중의 아동의 음독은 추후 읽기 운율성 채점을 위해 MP3 형식으로 오디오 녹음을 하였다.

읽기 운율성 검사는 읽기 자동성 검사 시 녹음된 아동의 음독에 대해 스펙트로그램을 활용해 운율성 하위요소에 대해 평가하는 방식으로 이루어졌다. 스펙트로그램 분석에는 Praat (version 6.0.36) 를 이용하였다. Praat는 시간에 따른 음도와 강도의 변이를 시각적 으로 분석할 수 있을 뿐만 아니라 단어 사이의 휴지 시간을 정확하 게 측정할 수 있는 음성분석프로그램이다(Yang, 2003). 스펙트로 그램을 활용해 읽기 운율성과 읽기이해의 사이의 관계를 알아본 선행연구들에서도 Praat가 사용되었다(Benjamin \& Schwanenflugel, 2010; Miller \& Schwanenflugel, 2006, 2008; Schwanenflugel et al., 2004). 다음과 같은 4 가지 운율성 하위요소에 대해 스펙 트로그램 분석이 이루어졌다.

\section{구두점 주의}

아동의 음성을 듣는 동시에 스펙트로그램을 보며 아동이 문장 내 구두점에 주의하며 구두점에서 끊어 읽기를 하였는지를 확인하 였다(Arcand et al., 2014). Miller와 Schwanenflugel (2008)에 따라 구두점 앞 어절의 음독이 끝나고 구두점 뒤 어절의 음독이 시작되 기 전까지 $100 \mathrm{~ms}$ 이상 묵음을 보였으면 구두점에 주의하며 끊어
읽기 한 것으로 평가하였다. 구두점 분석은 해당 학년 이야기글 내 의 구두점(온점, 반점, 물음표) 10 개에 대해 이루어졌고, 아동이 구 두점에서 끊어 읽기를 한 경우 1 점씩 부여하였다. 아동이 받을 수 있는 최대 점수는 10 점이다.

\section{부적절 휴지}

아동의 음성을 듣는 동시에 스펙트로그램을 보며 음독 중 100 $\mathrm{ms}$ 이상 묵음을 보인 경우 휴지로 간주(Miller \& Schwanenflugel, 2008)하고, 해당 휴지가 적절한 휴지였는지 부적절한 휴지였는지 를 확인하였다. 선행연구에서는 문장의 끝, 구두점, 의미단위 경계 에서 휴지를 둔 것은 적절한 휴지(Kim, 2011; Ryu, 2016)로, 어절단 위나 구문단위 내에서 휴지를 둔 것은 부적절한 휴지(Miller \& Schwanenflugel, 2008)로 평가하였다. 그러나 구문단위 내에서도 화자 의 의도에 따라 휴지를 둘 수 있으므로 휴지를 두는 구문단위 경계 에 대해 절대적인 기준을 세우기는 어렵다는 보고(Kim, 2008; Ryu, 2016)가 있어 본 연구에서는 어절단위 내에서 휴지를 둔 것만 부적 절한 휴지로 간주하고 아동이 해당 학년 설명글 내 10 문장을 읽는 동안 부적절한 휴지를 보인 총수를 기록하였다.

\section{평서문 끝에서의 음도 변화}

아동의 음독 중 평서문에 대해 음도 분석을 하여 문장 끝에서 음 도가 어느 정도 하강하는지 확인하였다. 평서문에서의 음도변화 분석은 해당 학년 설명글 내 3문장(평서문)에 대해 이루어졌다. 각 문장 마지막 어절의 음도곡선 마루(peak)의 기본주파수(fundamental frequency, $\left.\mathrm{F}_{0}\right)$ 값에서 문장 끝에서의 기본주파수 $\left(\mathrm{F}_{0}\right)$ 값을 빼서 구한 뒤, 3 개 문장의 평균값을 구하여 기록하였다(Benjamin \& Schwanenflugel, 2010; Miller \& Schwanenflugel, 2006, 2008; Schwanenflugel et al., 2004). 측정값은 소수 둘째 자리에서 반올림하여 소 수 첫째 자리까지만 기록하였고, 단위는 $\mathrm{Hz}$ 이다.

\section{의문문 끝에서의 음도 변화}

아동의 음독 중 의문문에 대해 음도 분석을 하여 문장 끝에서 음 도가 어느 정도 상승하는지 확인하였다. 의문문에서의 음도변화 분석은 해당 학년 이야기글 및 설명글 내 3 문장(의문문)에 대해 이 루어졌다. 각 문장 끝에서의 기본주파수 $\left(\mathrm{F}_{0}\right)$ 값에서 문장 마지막 어절의 음도곡선 골(valley)의 기본주파수 $\left(\mathrm{F}_{0}\right)$ 값을 빼서 구한 뒤, 3 개 문장의 평균값을 구하여 기록하였다(Miller \& Schwanenflugel, 2006). 측정값은 소수 둘째 자리에서 반올림하여 소수 첫째 자 리까지만 기록하였고, 단위는 $\mathrm{Hz}$ 이다.

어휘 검사는 수용 - 표현어휘력검사(REVT)의 수용어휘력검사 
원점수를 사용하였다. 읽기이해 검사는 한국어 읽기검사(KOLRA) 의 읽기이해검사 원점수를 사용하였다. 읽기이해 과제는 한 문단의 덩이 글을 읽고 빈칸에 알맞은 접속사, 조사, 어미, 피동 및 사동 표 현, 한자어, 속담 등을 쓰는 빈칸 채우기 형식이다.

\section{통계처리 및 신뢰도}

학년 간 읽기 자동성, 어휘, 읽기이해에서 유의한 차이가 있는지 알아보기 위하여 각각 일원배치분산분석(one-way ANOVA)을 실 시하였다. 학년 간 읽기 운율성(구두점 주의, 부적절 휴지, 평서문 끝 음도변화, 의문문 끝 음도변화)에서 유의한 차이가 있는지 알아 보기 위해 다변량 분산분석(MANOVA)을 실시하였다. 각 학년의 읽기이해, 읽기 자동성, 읽기 운율성, 어휘 간의 상관관계를 알아보 기 위하여 Pearson 상관분석을 실시하였다. 각 학년의 읽기이해를 예측하는 변인은 무엇인지 알아보기 위해 종속변수는 읽기이해로, 독립변수는 읽기 자동성, 읽기 운율성, 어휘로 하여 단계별 중다회 귀분석(stepwise multiple regression analysis)을 실시하였다. 자료 분석은 IBM SPSS Statistics version 23을 사용하였다. 전체 검사자 료의 $20 \%$ 에 해당하는 자료에 대해 평가자 간 신뢰도를 산출한 결 과, 어휘 신뢰도 $100 \%$, 읽기 자동성 신뢰도 $93.33 \%$, 읽기 운율성 신 뢰도 $90 \%$, 읽기이해 신뢰도 $100 \%$ 로 나타났다.

\section{연구결과}

\section{학년 간 읽기 자동성, 읽기 운율성, 어휘, 읽기이해 차이}

학년 간 읽기 자동성에서 유의한 차이가 있는지 알아보기 위해 일원배치분산분석(one-way ANOVA)을 실시한 결과, 학년 간 읽기

Table 2. Reading automaticity difference between grades

\begin{tabular}{lccccc}
\hline & $\begin{array}{l}\text { Grade 2 } \\
(\mathrm{N}=25)\end{array}$ & $\begin{array}{c}\text { Grade 3 } \\
(\mathrm{N}=24)\end{array}$ & $\begin{array}{c}\text { Grade 4 } \\
(\mathrm{N}=27)\end{array}$ & $F$ & Post hoc \\
\hline Reading & 146.80 & 147.46 & 175.00 & $8.066^{* *}$ & $\mathrm{G} 2<\mathrm{G} 4$ \\
automaticity & $(42.01)$ & $(23.71)$ & $(15.14)$ & & $\mathrm{G} 3<\mathrm{G} 4$ \\
\hline
\end{tabular}

Values are presented as mean (SD).

${ }^{* *} p<.01$.
자동성에서 유의한 차이가 나타났다 $\left(F_{(2,73)}=8.066, p<.01\right)$. 각 학 년의 차이를 구체적으로 알아보기 위해 Scheffe 사후검정을 실시 한 결과, 유의수준 .05 에서 2 학년과 4 학년 간, 3 학년과 4 학년 간 유 의한 차이를 보인 반면, 2 학년과 3 학년 간에는 유의한 차이가 나타 나지 않아 유의수준 .05에서 동질적 집합으로 묶였다. 이에 대한 결 과는 Table 2에 제시하였다.

학년 간 읽기 운율성 하위요소별로 유의한 차이가 있는지 알아보 기 위해 다변량 분산분석(MANOVA)을 실시한 결과, 읽기 운율성 에서 학년 간 유의한 차이가 나타나지 않았다(Wilks lambda $=.893$, $\left.F_{(8,140)}=1.015, p>.05\right)$. 이에 대한 결과는 Table 3에 제시하였다.

학년 간 어휘에서 유의한 차이가 있는지 알아보기 위해 일원배 치분산분석(one-way ANOVA)을 실시한 결과, 학년 간 어휘에서 유의한 차이가 나타났다 $\left(F_{(2,73)}=36.738, p<.001\right)$. 각 학년의 차이 를 구체적으로 알아보기 위해 Scheffe 사후검정을 실시한 결과, 유 의수준 .05 에서 2 학년과 3 학년 간, 2 학년과 4 학년 간, 3 학년과 4 학년 간 유의한 차이를 보였다. 이에 대한 결과는 Table 4에 제시하였다.

학년 간 읽기이해에서 유의한 차이가 있는지 알아보기 위해 일원 배치분산분석(one-way ANOVA)을 실시한 결과, 학년 간 읽기이해 에서 유의한 차이가 나타났다 $\left(F_{(2,73)}=38.601, p<.001\right)$. 각 학년의 차 이를 구체적으로 알아보기 위해 Scheffe 사후 검정을 실시한 결과, 유 의수준 .05 에서 2 학년과 3 학년 간, 2 학년과 4 학년 간, 3 학년과 4 학년 간 유의한차이를 보였다. 이에 대한 결과는 Table 5에 제시하였다.

\section{읽기이해와 읽기 자동성, 읽기 운율성, 어휘의 상관관계}

읽기이해와 읽기 자동성, 읽기 운율성(구두점 주의, 부적절 휴지, 평서문 끝 음도변화, 의문문 끝 음도변화), 어휘의 상관관계를 살펴

Table 4. Vocabulary difference between grades

\begin{tabular}{cccccc}
\hline & Grade 2 & Grade 3 & Grade 4 & F & Post hoc \\
& $(\mathrm{N}=25)$ & $(\mathrm{N}=24)$ & $(\mathrm{N}=27)$ & & \\
\hline Vocabulary & 94.20 & 105.83 & 123.11 & $36.738^{* * *}$ & $\mathrm{G} 2<\mathrm{G} 3$ \\
& $(12.13)$ & $(8.82)$ & $(14.73)$ & & $\mathrm{G} 2<\mathrm{G} 4$ \\
& & & & $\mathrm{G} 3<\mathrm{G} 4$ \\
\hline
\end{tabular}

Values are presented as mean (SD).

${ }^{* * *} p<.001$.

Table 3. Reading prosody difference between grades

\begin{tabular}{|c|c|c|c|c|c|}
\hline & Grade $2(\mathrm{~N}=25)$ & Grade $3(\mathrm{~N}=24)$ & Grade 4 (N=27) & $F$ & Sig \\
\hline Attention to punctuation & $7.12(2.17)$ & $6.46(2.26)$ & $7.59(1.55)$ & 2.043 & .137 \\
\hline Inappropriate pause & $3.16(4.28)$ & $2.08(3.12)$ & $1.78(2.31)$ & 1.225 & .300 \\
\hline Declarative $-F_{0}$ change & 76.64 (42.74) & $65.30(23.36)$ & $73.26(27.31)$ & .800 & .453 \\
\hline Questions - $F_{0}$ change & $102.38(55.06)$ & 97.00 (63.06) & 88.22 (49.94) & .425 & .655 \\
\hline
\end{tabular}

Values are presented as mean (SD). 
보기 위해각 학년별로 Pearson 상관분석을 실시하였다.

2학년 아동(25명)을 대상으로 변인 간 상관관계를 분석한 결과, 읽기이해는 유의수준 .01에서 읽기 자동성 $(r=.647)$, 어휘 $(r=.511)$ 와 유의한 상관을 보였고, 유의수준 .05에서 부적절 휴지 $(r=-.496)$ 와 유의한 상관을 보였다. 읽기 자동성은 유의수준 .01에서 부적절 휴지 $(r=-.769)$, 어휘 $(r=.594)$ 와 유의한 상관을 보였다. 구두점 주의 는 유의수준 .05 에서 평서문 끝 음도변화 $(r=.433)$ 와 유의한 상관을 보였고, 평서문 끝 음도변화는 유의수준 .05에서 의문문 끝 음도변 화 $(r=.406)$ 와 유의한 상관을 보였다. 이에 대한 결과는 Table 6에 제시하였다.

3 학년 아동(24명)을 대상으로 변인 간 상관관계를 분석한 결과, 읽기이해는 유의수준 .01 에서 읽기 자동성 $(r=.535)$ 과 유의한 상관

Table 5. Reading comprehension difference between grades

\begin{tabular}{cccccc}
\hline & $\begin{array}{c}\text { Grade 2 } \\
(\mathrm{N}=25)\end{array}$ & $\begin{array}{c}\text { Grade 3 } \\
(\mathrm{N}=24)\end{array}$ & $\begin{array}{c}\text { Grade 4 } \\
(\mathrm{N}=27)\end{array}$ & $F$ & Post hoc \\
\hline $\begin{array}{c}\text { Reading com- } \\
\text { prehension }\end{array}$ & $10.28(3.22)$ & $13.00(3.20)$ & $17.67(2.80)$ & $38.601^{* * *}$ & $\mathrm{G} 2<\mathrm{G} 3$ \\
& & & & & $\mathrm{G} 2<\mathrm{G} 4$ \\
$\mathrm{G} 3<\mathrm{G} 4$
\end{tabular}

Values are presented as mean (SD).

${ }^{* * *} p<.001$.
을 보였고, 유의수준 .05에서 어휘 $(r=.505)$ 와 유의한 상관을 보였 다. 읽기 자동성은 유의수준 .05에서 부적절 휴지 $(r=-.416)$ 와 유의 한 상관을 보였다. 구두점 주의는 유의수준.05에서 평서문 끝 음도 변화 $(r=.467)$ 와 유의한 상관을 보였고, 부적절 휴지는 유의수준 .05 에서 어휘 $(r=-.494)$ 와 유의한 상관을 보였다. 이에 대한 결과는

Table 7에 제시하였다.

4 학년 아동(27명)을 대상으로 변인 간 상관관계를 분석한 결과, 읽기이해는 유의수준 .01에서 어휘 $(r=.505)$, 읽기 자동성 $(r=.504)$, 부적절 휴지 $(r=-.493)$ 와 유의한 상관을 보였다. 읽기 자동성은 유 의수준 .01에서 어휘 $(r=.609)$, 부적절 휴지 $(r=-.555)$ 와 유의한 상 관을 보였다. 구두점 주의는 유의수준 .01에서 어휘 $(r=-.508)$ 와 유 의한 상관을 보였다. 이에 대한 결과는 Table 8에 제시하였다.

\section{읽기이해 예측변인}

읽기 자동성, 읽기 운율성(구두점 주의, 부적절 휴지, 평서문 끝 음도변화, 의문문 끝 음도변화), 어휘의 읽기이해 예측력을 살펴보 기 위해 각 학년별로 단계별 중다회귀분석(stepwise multiple regression analysis)을 실시하였다.

2학년 아동(25명)의 읽기이해를 예측하는 변인 단계별 중다회귀 분석 결과, 읽기 자동성이 읽기이해를 $41.9 \%$ 예측하는 것으로 나타

Table 6. Correlations between reading comprehension and other variables for children who are grade 2

\begin{tabular}{|c|c|c|c|c|c|c|}
\hline & $\begin{array}{c}\text { Reading } \\
\text { comprehension }\end{array}$ & $\begin{array}{c}\text { Reading } \\
\text { automaticity }\end{array}$ & $\begin{array}{l}\text { Attention to } \\
\text { punctuation }\end{array}$ & $\begin{array}{l}\text { Inappropriate } \\
\text { pause }\end{array}$ & $\begin{array}{l}\text { Declarative }-F_{0} \\
\text { change }\end{array}$ & $\begin{array}{l}\text { Questions - } F_{0} \\
\text { change }\end{array}$ \\
\hline Reading comprehension & - & & & & & \\
\hline Reading automaticity & $.647^{* *}$ & & & & & \\
\hline Attention to punctuation & -.136 & -.315 & & & & \\
\hline Inappropriate pause & $-.496^{*}$ & $-.769^{* *}$ & .393 & & & \\
\hline Declarative $-F_{0}$ change & .068 & .010 & $.433^{*}$ & .170 & & \\
\hline Questions - $\mathrm{F}_{0}$ change & .119 & .069 & .121 & .080 & $.406^{*}$ & \\
\hline Vocabulary & $.511^{* *}$ & $.594^{* *}$ & -.155 & -.261 & -.045 & -.046 \\
\hline
\end{tabular}

${ }^{*} p<.05,{ }^{* *} p<.01$.

Table 7. Correlations between reading comprehension and other variables for children who are grade 3

\begin{tabular}{|c|c|c|c|c|c|c|}
\hline & $\begin{array}{c}\text { Reading } \\
\text { comprehension }\end{array}$ & $\begin{array}{c}\text { Reading } \\
\text { automaticity }\end{array}$ & $\begin{array}{l}\text { Attention to } \\
\text { punctuation }\end{array}$ & $\begin{array}{l}\text { Inappropriate } \\
\text { pause }\end{array}$ & $\begin{array}{c}\text { Declarative }-F_{0} \\
\text { change }\end{array}$ & $\begin{array}{c}\text { Questions }-F_{0} \\
\text { change }\end{array}$ \\
\hline Reading comprehension & - & & & & & \\
\hline Reading automaticity & $.535^{* *}$ & & & & & \\
\hline Attention to punctuation & -.048 & -.134 & & & & \\
\hline Inappropriate pause & -.292 & $-.416^{*}$ & -.233 & & & \\
\hline Declarative $-F_{0}$ change & .176 & .039 & $.467^{*}$ & -.188 & & \\
\hline Questions - $\mathrm{F}_{0}$ change & .211 & .160 & .222 & .100 & .035 & \\
\hline Vocabulary & $.505^{*}$ & .391 & .050 & $-.494^{*}$ & -.052 & .089 \\
\hline
\end{tabular}

${ }^{*} p<.05,{ }^{* *} p<.01$. 
Ji Yeon Lee, et al. • Reading Automaticity and Prosody in Reading Comprehension

Table 8. Correlations between reading comprehension and other variables for children who are grade 4

\begin{tabular}{|c|c|c|c|c|c|c|}
\hline & $\begin{array}{c}\text { Reading } \\
\text { comprehension }\end{array}$ & $\begin{array}{c}\text { Reading } \\
\text { automaticity }\end{array}$ & $\begin{array}{l}\text { Attention to } \\
\text { punctuation }\end{array}$ & $\begin{array}{l}\text { Inappropriate } \\
\text { pause }\end{array}$ & $\begin{array}{l}\text { Declarative }-F_{0} \\
\text { change }\end{array}$ & $\begin{array}{l}\text { Questions - } F_{0} \\
\text { change }\end{array}$ \\
\hline Reading comprehension & - & & & & & \\
\hline Reading automaticity & $.504^{* *}$ & & & & & \\
\hline Attention to punctuation & -.094 & -.054 & & & & \\
\hline Inappropriate pause & $-.493^{* *}$ & $-.555^{* *}$ & -.316 & & & \\
\hline Declarative $-F_{0}$ change & -.127 & .167 & .230 & -.036 & & \\
\hline Questions $-F_{0}$ change & -.034 & -.313 & .190 & .049 & .288 & \\
\hline Vocabulary & $.505^{* *}$ & $.609^{* *}$ & $-.508^{* *}$ & -.217 & -.185 & -.321 \\
\hline
\end{tabular}

${ }^{* *} p<.01$.

Table 9. Stepwise multiple regression analysis predicting reading comprehension for children who are grade 2

\begin{tabular}{|c|c|c|c|c|c|}
\hline & B & $\beta$ & $\mathrm{R}^{2}$ & Adj. $R^{2}$ & $F$ \\
\hline Step 1 & & & .419 & .394 & $16.590^{* * *}$ \\
\hline Reading automaticity & .050 & $.647^{* * *}$ & & & \\
\hline
\end{tabular}

${ }^{* * *} p<.001$.

Table 10. Stepwise multiple regression analysis predicting reading comprehension for children who are grade 3

\begin{tabular}{|c|c|c|c|c|c|}
\hline & B & $\beta$ & $\mathrm{R}^{2}$ & Adj. $R^{2}$ & $F$ \\
\hline Step 1 & & & .287 & .254 & $8.837^{* *}$ \\
\hline Reading automaticity & .072 & $.535^{* *}$ & & & \\
\hline
\end{tabular}

${ }^{* *} p<.01$.

났다. 다른 변인은 읽기이해를 예측하지 못하는 것으로 나타났다. 2 학년 아동의 중다회귀분석 결과는 Table 9 와 같다.

3 학년 아동(24명)의 읽기이해를 예측하는 변인 단계별 중다회귀 분석 결과, 읽기 자동성이 읽기이해를 $28.7 \%$ 예측하는 것으로 나타 났다. 다른 변인은 읽기이해를 예측하지 못하는 것으로 나타났다. 3 학년 아동의 중다회귀분석 결과는 Table 10 과 같다.

4 학년 아동(27명)의 읽기이해를 예측하는 변인 단계별 중다회귀 분석 결과, 어휘와 부적절 휴지가 읽기이해를 $41.0 \%$ 예측하는 것으 로 나타났다. 각 변인을 자세히 살펴보면 어휘는 예측력이 $25.5 \%$ 로 읽기이해를 예측하는 가장 큰 변인으로 나타났고, 부적절 휴지는 읽기이해를 $15.5 \%$ 추가 예측하는 것으로 나타났다. 4 학년 아동의 중다회귀분석 결과는 Table 11과같다.

\section{논의 및 결론}

본 연구는 초등학교 2-4학년 일반아동을 대상으로 학년 간 읽기 자 동성 및 운율성차이를확인하고, 학년에 따라읽기자동성과운율성이 읽기이해에 미치는 영향에 있어차이가 있는지를알아보고자하였다.
Table 11. Stepwise multiple regression analysis predicting reading comprehension for children who are grade 4

\begin{tabular}{lccccc}
\hline & $\mathrm{B}$ & $\beta$ & $\mathrm{R}^{2}$ & Adj. $\mathrm{R}^{2}$ & $\mathrm{~F}$ \\
\hline Step 1 & & & .255 & .225 & $8.566^{* *}$ \\
$\quad$ Vocabulary & .096 & $.505^{* *}$ & & & \\
Step 2 & & & .410 & .360 & $8.328^{* *}$ \\
$\quad$ Vocabulary & .079 & $.418^{*}$ & & & \\
$\quad$ Inappropriate pause & -.488 & $-.403^{*}$ & & & \\
\hline
\end{tabular}

${ }^{*} p<.05,{ }^{* *} p<.01$.

학년 간 읽기 자동성 및 운율성 수행력에서 유의한 차이가 있는 지를 알아본 결과, 읽기 자동성에서는 학년 간 유의한 차이가 나타 났다. 사후검정 결과, 2,3 학년은 읽기 자동성에 있어 유의한 차이 가 나지 않아 동질적 집합으로 묶였고, 4 학년은 2,3 학년 보다 읽기 자동성에서 유의하게 높은 수행을 보여 다른 집합으로 나뉘었다. 이는 읽기 자동성이 저학년에 비해 고학년에서 유의미하게 높은수 행력을 보인다는 선행연구 결과와 일치한다(Calet et al., 2015; Kim et al., 2010; Kim \& Pae, 2012). 또한, Chall (1983)의 읽기 발달 단계 와도 일치하는데 Chall (1983)에 따르면 2, 3학년은 읽기 자동성이 발달하고 있는 단계에 있고, 4 학년은 정확하고 빨라진 읽기 자동성 을 바탕으로 읽기 자료의 내용에 보다주의를 기울이는 단계에 있다. 읽기 운율성에서는 학년 간 유의한 차이가 나타나지 않았다. 이 는 3, 5, 7학년 학생을 대상으로 읽기 운율성을 평가하였을 때 학년 간 유의한 차이가 나지 않았던 선행연구(Rasinski et al., 2009) 결과 와 일치한다. Rasinski 등(2009)은 읽기 운율성에서 학년 간 유의한 차이가 나타나지 않은 것은 학교에서 읽기 유창성 교육 시 운율성 측면의 교육이 이루어지지 않은 것과 관련된다고 보며 읽기 운율성 교육의 필요성을 언급하였다. 그러나 Álvarez-Cañizo, SuárezCoalla와 Cuetos (2018)의 연구에서는 3학년, 5 학년의 읽기 운율성 을 성인의 읽기 운율성과 비교하였는데 3학년과 달리 5 학년은 성인 의 운율성과 유사하게 나타났다고 보고하며 학년이 올라갈수록 읽 기 경험이 많아짐에 따라 읽기 운율성이 향상된다고 보았다. 또한, 
Calet 등(2015)의 연구에서도 2 학년에 비해 4 학년의 읽기 운율성이 유의하게 높은 것으로 나타났다. 본 연구결과 학년 간 읽기 운율성 에서 유의한 차이가 나타나지 않은 것은 본 연구의 운율성 평가방 법 및 평가요소에서 원인을 찾아볼 수도 있을 것이다. 한글에서 읽 기 운율성 수행력을 잘 확인할 수 있는 평가방법 및 요소가 무엇인 지 확인할 필요가 있을 것이다.

각 학년에서 읽기이해를 예측하는 요인이 무엇인지 알아보기 위 해 독립변수를 읽기 자동성, 읽기 운율성, 어휘로 하여 단계별 중다 회귀분석을 실시한 결과, 2 학년의 읽기이해 예측변인은 읽기 자동 성으로 읽기이해를 $41.9 \%$ 예측하는 것으로 나타났다. 3 학년의 읽 기이해 예측변인도 읽기 자동성으로 읽기이해를 $28.7 \%$ 예측하는 것으로 나타났다. 4 학년에서는 어휘와 부적절 휴지가 읽기이해를 $41.0 \%$ 예측하는 것으로 나타났다. 어휘는 예측력이 $25.5 \%$ 로 읽기 이해를 예측하는 가장 큰 변인으로 나타났고, 부적절 휴지는 읽기 이해를 $15.5 \%$ 추가 예측하는 것으로 나타났다. 즉, 2 학년과 3 학년 의 읽기이해 예측변인이 같았고, 4 학년은 2,3 학년과 달랐다. 이는 학년이 올라감에 따라 읽기이해를 예측하는 변인은 변한다고 보고 한 선행연구를 지지하는 결과라고 볼 수 있다(Catts, Fey, Tomblin, \& Zhang, 2002). 또한 2, 3학년과 4학년의 읽기이해 예측변인이 다 르게 나타난 것은 2,3 학년과 4 학년의 읽기 자동성 수행력의 차이 때문인 것으로 생각해 볼 수 있다. LaBerge와 Samuels (1974)의 자 동성 이론에 따르면 비교적 정확하고 빠르게 글자를 해독할 수 있 다면 글을 읽는 동안 대부분의 인지적 자원을 읽은 자료를 통합하 여 해석하는 읽기이해에 사용할 수 있어 읽기이해에서 높은 수행 을 보이는 반면, 느린 속도로 대부분의 인지적 자원을 글을 정확하 게 읽는데 사용하게 되면 읽기이해에 사용할 인지적 자원이 없게 되어 읽기이해에 실패하게 된다. 선행연구에서도 성공적인 읽기이 해에 있어 읽기 자동성의 역할이 매우 중요한데 이 역할은 읽기 자 동성이 발달하고 있는 단계에서 보다 중요하다고 하였다(Adlof, Catts, \& Little, 2006; Calet et al., 2015; Valencia et al., 2010). 또한 선행연구에 따르면 읽기 자동성이 천정효과에 도달하면 읽기 자동 성의 읽기이해 설명력이 약해지고 다른 요인이 읽기이해에 더 중요 한 역할을 하게 되며(Adlof et al., 2006; Gough, Hoover, \& Peterson, 1996), 고학년이 될수록 어휘, 구문지식 등의 언어능력이 읽기이해 에 더 중요한 역할을 하게 된다고 보고되고 있다(Gough et al., 1996). 본 연구에서도 4학년의 읽기이해를 예측하는 가장 큰 변인은 어휘 인 것으로 나타났다. 어휘 외 읽기 운율성 요소인 부적절 휴지도 4 학년의 읽기이해를 예측할 수 있었는데 이는 학년이 올라갈수록 읽 기 운율성의 읽기이해 설명력이 커진다는 선행연구 결과와 일치한 다(Calet et al., 2015; Valencia et al., 2010). Kuhn과 Stahl (2003)에
따르면 아동은 읽기 자동성이 확고해진 후에야 읽기이해를 돕기 위 해 운율성 요소를 사용하므로 4 학년에서는 읽기 자동성보다 운율 성이 읽기이해에 더 중요한 역할을 했다고 볼 수 있다. 본 연구에서 는 읽기 운율성 하위요소 중 부적절 휴지만 읽기이해를 예측할 수 있었고, 다른 요소들은 읽기이해를 예측할 수 없는 것으로 나타났 다. 이와 같은 결과는 부적절한 휴지가 읽기이해를 예측하는 중요한 변인임을 확인한 선행연구(Arcand et al., 2014; Miller \& Schwanenflugel, 2008; Valencia et al., 2010)를 뒷받침하며 의미단위 끊어 읽 기 중재를 통해 끊어 읽기와 적절한 휴지가 읽기이해에 중요한 요소 임을 밝힌 선행연구(Jeong, 2007; Kim, 2011)를 지지해준다. 독자는 우선 낱말을 해독한 뒤 낱말을 유의미 단위로 묶으며 글의 의미를 이해하게 되는데 끊어 읽기, 휴지, 억양 등과 같은 운율적 요인들은 낱말을 유의미 단위로 묶는데 필요한 통사적 정보를 제공해주기 때문에 읽기이해에 중요하다(McKenna \& Stahl, 2003). 그런데 부 적절한 휴지는 낱말을 의미가 없거나 의도된 의미에서 벗어나게 묶 어버리기 때문에 글의 의미를 이해하는 것을 방해하게 된다(Arcand et al., 2014).

본 연구에서는 구두점 주의와 평서문 및 의문문 끝에서의 음도 변화는 읽기이해를 예측할 수 없는 요소로 나타났다. 이는 Arcand 등(2014)의 연구에서 구두점 주의가 읽기이해를 예측할 수 있는 운 율성 요소라는 결과와 다소 차이가 있는데 이는 본 연구와 구두점 주의 평가방법에서 차이가 있기 때문인 것으로 보인다. 본 연구는 글을 읽는 동안 구두점에서 적절하게 휴지를 둔 총 수를 기록하였 고, Arcand 등(2014)의 연구는 글을 읽는 동안 보인 적절한 휴지 수 를 글에 있는 구두점 총수로 나누어서 기록하였다. Calet 등(2015), Miller와 Schwanenflugel (2008)의 연구에서는 억양이 읽기이해를 예측하는 운율성 요소로 밝혀졌는데 본 연구와 억양 평가방법이 달랐다. 본 연구는 억양을 평서문 및 의문문 끝에서 음도변화 정도 로 측정한 반면, Calet 등(2015)의 연구에서는 대상자가 글을 소리 내어 읽는 것을 듣고 평가자가 평가 척도를 활용하여 점수를 매기 는 방법으로 억양을 평가하였고, Miller와 Schwanenflugel (2008) 의 연구에서는 아동과 성인의 억양곡선 일치 정도로 억양을 평가 하여 평가방법의 차이로 본 연구와 다른 결과를 보인 것으로 추측 해볼수 있다.

본 연구는 읽기 유창성 평가 시 유창성의 세 가지 요소인 정확성, 신속성, 운율성 중 정확성과 신속성에 해당하는 읽기 자동성에 대 한 평가만 주로 이루어지고 읽기 운율성에 대한 평가는 미비한 실 정에서, 운율성을 포함하여 학령기 아동의 읽기 유창성과 읽기이 해의 관계를 살펴보았다는 점에서 의의가 있다. 연구 결과, 아직 읽 기 자동성이 발달하고 있는 초등 2,3 학년에서는 읽기 자동성이 읽 
기이해를 예측하는 변인으로 나타났고, 읽기 자동성이 어느 정도 숙달된 초등 4학년에서는 어휘와 읽기 운율성 요소인 부적절 휴지 가 읽기이해를 예측할 수 있는 것으로 나타났다. 이는 학령기 아동 의 읽기 유창성 평가 시 자동성 평가뿐 아니라 운율성 평가도 함께 이루어지는 것이 필요하며 학년에 따라 주의 깊게 봐야 할 읽기 유 창성 요소가 다름을 시사한다. 뿐만 아니라 임상이나 교육현장에 서 읽기 유창성 중재를 실시함에 있어 자동성에 대한 중재뿐 아니 라 적절하게 휴지를 두며 의미단위로 끊어 읽는 운율성에 대한 중 재가 함께 이루어질 필요가 있음을 시사한다.

본 연구의 제한점은 빈칸 채우기 형식으로만 아동의 읽기이해 능 력을 평가하였다는 점이다. 선행연구에 따르면 읽기이해를 평가하 는 검사 형식은 '빈 칸 채우기', '예/아니오 반응, '선다형 평가', '개방 형 질문, '다시 말하기’ 등으로 다양하며 검사 형식에 따라 읽기이 해를 설명할 수 있는 변인에 있어 차이를 보이는 것으로 나타났다 (Chung, Kim, \& Yoon, 2017; Francis et al., 2006). 후속연구에서는 빈칸 채우기 형식 외 다른 검사 형식도 포함하여 아동의 읽기이해 능력을 평가한다면 읽기 자동성 및 운율성의 읽기이해 설명력을 좀 더 정확히 파악할 수 있을 것으로 보인다. 또한, 읽기 운율성 하 위요소인 억양에 대한 평가 시 문장 끝부분에 국한해서 음도변화 를 확인한 점과 제시된 문장의 길이가 학년에 따라 차이가 있어 문 장의 길이가 통제되지 않았다는 점에서 제한점이 있다. 후속 연구 에서는 문장 끝부분의 음도변화만 확인하는 것이 아니라 문장 전 체에 대한 음도변화를 확인하는 것이 필요할 것으로 보인다. 이 외 에도 본 연구는 일반아동만을 대상으로 하였으나 후속연구에서는 읽기부진 아동을 연구대상에 포함시켜 일반아동과 어떤 차이가 있는지 살펴본다면 임상현장에 유익한 정보를 제공할 수 있을 것 으로 보인다.

\section{REFERENCES}

Adlof, S. M., Catts, H. W., \& Little, T. D. (2006). Should the simple view of reading include a fluency component? Reading and Writing, 19(9), 933958.

Álvarez-Cañizo, M., Suárez-Coalla, P., \& Cuetos, F. (2018). Reading prosody development in Spanish children. Reading and Writing, 31(1), 35-52.

Arcand, M. S., Dion, E., Lemire-Théberge, L., Guay, M. H., Barrette, A., Gagnon, V., ... \& Fuchs, D. (2014). Segmenting texts into meaningful word groups: beginning readers' prosody and comprehension. Scientific Studies of Reading, 18(3), 208-223.

Benjamin, R. G., \& Schwanenflugel, P. J. (2010). Text complexity and oral reading prosody in young readers. Reading Research Quarterly, 45(4), 388404.

Calet, N., Gutiérrez-Palma, N., \& Defior, S. (2015). A cross-sectional study of fluency and reading comprehension in Spanish primary school children. Journal of Research in Reading, 38(3), 272-285.

Calet, N., Gutiérrez-Palma, N., \& Defior, S. (2017). Effects of fluency training on reading competence in primary school children: the role of prosody. Learning and Instruction, 52, 59-68.

Catts, H. W., Fey, M. E., Tomblin, J. B., \& Zhang, X. (2002). A longitudinal investigation of reading outcomes in children with language impairments. Journal of Speech, Language, and hearing Research, 45(6), 1142-1157.

Chall, J. S. (1983). Stages of reading development. New York, NY: McGrawHill.

Chung, B. J., Kim, Y. T., \& Yoon, H. J. (2017). Relative contributions of components to different reading comprehension tasks in grade 3-4. Communication Sciences \& Disorders, 22(1), 66-75.

Cowie, R., Douglas-Cowie, E., \& Wichmann, A. (2002). Prosodic characteristics of skilled reading: fluency and expressiveness in 8-10-year-old readers. Language and Speech, 45(1), 47-82.

Dowhower, S. L. (1991). Speaking of prosody: fluency's unattended bedfellow. Theory into Practice, 30(3), 165-175.

Francis, D. J., Snow, C. E., August, D., Carlson, C. D., Miller, J., \& Iglesias, A. (2006). Measures of reading comprehension: a latent variable analysis of the diagnostic assessment of reading comprehension. Scientific Studies of Reading, 10(3), 301-322.

Fuchs, L. S., Fuchs, D., Hosp, M. K., \& Jenkins, J. R. (2001). Oral reading fluency as an indicator of reading competence: a theoretical, empirical, and historical analysis. Scientific Studies of Reading, 5(3), 239-256.

Gough, P. B., Hoover, W. A., \& Peterson, C. L. (1996). Some observations on a simple view of reacting. In C. Cornoldi \& J. Oakhill (Eds.), Reading comprehension difficulties: processes and intervention (pp. 1-13). Mahwah, NJ: Lawrence Erlbaum Associates.

Hock, M., \& Mellard, D. (2005). Reading comprehension strategies for adult literacy outcomes. Journal of Adolescent \& Adult Literacy, 49(3), 192-200.

Jeong, S. (2007). The effects of the meaning-centered sentence pause reading strategy on the reading fluency and comprehension of students with reading disabilities (Master's thesis). Chonnam National University, Gwangju, Korea.

Kim, A. H., \& Hwang, M. (2008). Prediction of reading skills in upper elementary students. Korean Journal of Communication \& Disorders, 13(1), 
$1-25$.

Kim, A. H., Park, S. H., \& Kim, J. H. (2010). Reading fluency of elementary students in Korea: reading developmental patterns and error patterns. Korean Journal of Communication \& Disorders, 15(1), 43-55.

Kim, A., Kim U., Hwang, M., \& Yoo, H. (2014). Test of Reading Achievement and Reading Cognitive Processes Ability (RA-RCP). Seoul: Hakjisa.

Kim, M., \& Pae, S. (2012). Reading skills and phonological processing abilities of Korean elementary school children with/without poor reading. Korean Journal of Communication \& Disorders, 17(4), 565-581.

Kim, S. H. (2008). A study on methodology to improve Korean reading ability through teaching sense groups. Bilingual Research, 38, 69-93.

Kim, S. J. (2011). The effects of the meaning-centered sentence pause reading strategy on reading fluency and comprehension of children with poor reading comprehension (Master's thesis). Seoul National University of Education, Seoul, Korea.

Kim, Y. S. G., \& Wagner, R. K. (2015). Text (oral) reading fluency as a construct in reading development: an investigation of its mediating role for children from grades 1 to 4. Scientific Studies of Reading, 19(3), 224-242.

Kim, Y. T., Hong, G. H., Kim, K. H., Jang, H. S., \& Lee, J. Y. (2009). Receptive \& expressive vocabulary test (REVT). Seoul: Seoul Community Rehabilitation Center.

Kuhn, M. R., \& Stahl, S. A. (2003). Fluency: a review of developmental and remedial practices. Journal of Educational Psychology, 95(1), 3-21.

Kuhn, M. R., Schwanenflugel, P. J., \& Meisinger, E. B. (2010). Aligning theory and assessment of reading fluency: automaticity, prosody, and definitions of fluency. Reading Research Quarterly, 45(2), 230-251.

LaBerge, D., \& Samuels, S. J. (1974). Toward a theory of automatic information processing in reading. Cognitive Psychology, 6(2), 293-323.

Landerl, K., \& Wimmer, H. (2008). Development of word reading fluency and spelling in a consistent orthography: an 8-year follow-up. Journal of Educational Psychology, 100(1), 150-161.

Lee, Y. \& Kim, J. (2009). The effects of RAAC intervention on reading performance of children with intellectual disabilities. Special Education Research, 8(2), 161-183.

Lyon, G. R., \& Moats, L. C. (1997). Critical conceptual and methodological considerations in reading intervention research. Journal of Learning Disabilities, 30(6), 578-588.

McKenna, M. C., \& Stahl, S. A. (2003). Assessment for reading instruction. New York, NY: Guilford Press.

Miller, J., \& Schwanenflugel, P. J. (2006). Prosody of syntactically complex sentences in the oral reading of young children. Journal of Educational Psychology, 98(4), 839-843.

Miller, J., \& Schwanenflugel, P. J. (2008). A longitudinal study of the development of reading prosody as a dimension of oral reading fluency in early elementary school children. Reading Research Quarterly, 43(4), 336-354.

Muter, V., Hulme, C., Snowling, M. J., \& Stevenson, J. (2004). Phonemes, rimes, vocabulary, and grammatical skills as foundations of early reading development: evidence from a longitudinal study. Developmental Psychology, 40(5), 665-681.

Nation, K., \& Snowling, M. J. (1999). Developmental differences in sensitivity to semantic relations among good and poor comprehenders: evidence from semantic priming. Cognition, 70(1), B1-B13.

Nation, K., Adams, J. W., Bowyer-Crane, C. A., \& Snowling, M. J. (1999). Working memory deficits in poor comprehenders reflect underlying language impairments. Journal of Experimental Child Psychology, 73(2), 139-158.

National Reading Panel. (2000). Teaching children to read: an evidence-based assessment of the scientific search literature on reading an implication for reading instruction. Washington, DC: National Institute of Child Health and Human Development.

Nippold, M. A. (2007). Later language development: school-age children, adolescents, and young adults (3rd ed.). Austin, TX: Pro-ED.

Ouellette, G. P. (2006). What's meaning got to do with it: The role of vocabulary in word reading and reading comprehension. Journal of Educational Psychology, 98(3), 554-566.

Pae, S., Kim, M., Yoon, H. J., \& Jang, S. (2015). Korean Language Based Reading Assessment (KOLRA). Seoul: Hakjisa.

Pressley, M., Duke, N. K., Gaskins, I. W., Fingeret, L., Halladay, J. L., Park, Y.,... \& Collins, S. (2009). Working with struggling readers: why we must get beyond the simple view of reading and visions of how it might be done. In T. B. Gutkin \& C. R. Reynolds (Eds.), The handbook of school psychology (4th ed., pp. 522-546). New York, NY: John Wiley \& Sons.

Rasinski, T., Rikli, A., \& Johnston, S. (2009). Reading fluency: more than automaticity? More than a concern for the primary grades? Literacy Research and Instruction, 48(4), 350-361.

Ravid, D., \& Mashraki, Y. E. (2007). Prosodic reading, reading comprehension and morphological skills in Hebrew-speaking fourth graders. Journal of Research in Reading, 30(2), 140-156.

Ryu, N. (2016). A study on teaching plans of reading Korean with pauses: targeting elementary school learners from multicultural backgrounds (Master's thesis). Gyeongin National University of Education, Incheon, Korea. 
Ji Yeon Lee, et al. • Reading Automaticity and Prosody in Reading Comprehension

Schreiber, P. A. (1980). On the acquisition of reading fluency. Journal of Reading Behavior, 12(3), 177-186.

Schwanenflugel, P. J., Hamilton, A. M., Kuhn, M. R., Wisenbaker, J. M., \& Stahl, S. A. (2004). Becoming a fluent reader: reading skill and prosodic features in the oral reading of young readers. Journal of Educational Psychology, 96(1), 119-129.

Seo, M. S. (2016). A study on the systematization of Korean Reading proficiency evaluation and development of an evaluation tool (Master's thesis). Gyeongin National University of Education, Incheon, Korea.

Song, Y. B. (2012). Study on the effects of oral reading-based Korean lessons on reading fluency and comprehension for multi-cultural Korean learners (Doctoral dissertation). Korea University, Seoul, Korea.

Stahl, S. A., \& Heubach, K. M. (2005). Fluency-oriented reading instruction. Journal of Literacy Research, 37(1), 25-60.

Tilstra, J., McMaster, K., Van den Broek, P., Kendeou, P., \& Rapp, D. (2009). Simple but complex: components of the simple view of reading across grade levels. Journal of Research in Reading, 32(4), 383-401.

Valencia, S. W., Smith, A. T., Reece, A. M., Li, M., Wixson, K. K., \& Newman, H. (2010). Oral reading fluency assessment: issues of construct, criterion, and consequential validity. Reading Research Quarterly, 45(3), 270-291.

Veenendaal, N. J., Groen, M. A., \& Verhoeven, L. (2015). What oral text read- ing fluency can reveal about reading comprehension. Journal of Research in Reading, 38(3), 213-225.

Wexler, J., Vaughn, S., Edmonds, M., \& Reutebuch, C. K. (2008). A synthesis of fluency interventions for secondary struggling readers. Reading and Writing, 21(4), 317-347.

Wolf, M., \& Katzir-Cohen, T. (2001). Reading fluency and its intervention. Scientific Studies of Reading, 5(3), 211-239.

Yang, B. (2003). Theory and practice of voice analysis using Praat. Busan: Mansu Publishers.

Yoon, H. (2015). Prediction of reading comprehension in early and late elementary grades: contribution of word decoding, vocabulary and syntactic knowledge. Communication Sciences \& Disorders, 20(4), 536-546.

Yoon, H., Pae, S., \& Chung, B. J. (2018). The role of vocabulary breadth and depth on reading comprehension in grade 1-4. Communication Sciences \& Disorders, 23(2), 519-527.

Young, C., Mohr, K. A., \& Rasinski, T. (2015). Reading together: a successful reading fluency intervention. Literacy Research and Instruction, 54(1), 6781.

Zutell, J., \& Rasinski, T. V. (1991). Training teachers to attend to their students' oral reading fluency. Theory into Practice, 30(3), 211-217. 


\title{
국문초록
}

\author{
초등학교 2-4학년 아동의 읽기 자동성 및 운율성과 읽기이해 관계 \\ 이지연 · 김영태2 · 강진경 \\ '언어학습연구소 정담, ${ }^{2}$ 이화여자대학교 언어병리학과
}

배경 및 목적: 본 연구는 초등학교 2-4학년 일반아동을 대상으로 읽기 자동성과 읽기 운율성 평가를 실시하여 학년에 따라 읽기 자동 성과 운율성이 읽기이해에 미치는 영향에 있어 차이가 있는지를 살펴보는데 목적이 있다. 방법: 연구는 초등학교 2학년 25 명, 3 학년 24 명, 4학년 27명으로 총 76 명의 일반아동을 대상으로 하였다. 종속변인으로 읽기이해, 읽기이해를 예측하는 독립변인으로 읽기 자동성, 읽기 운율성(구두점 주의, 부적절 휴지, 평서문 끝에서의 음도변화, 의문문 끝에서의 음도변화), 어휘를 검사하고 단계별 중다회귀분석 을 실시하였다. 결과: 2 학년과 3 학년의 읽기이해 예측 변인은 읽기 자동성으로 나타났고, 4 학년은 2,3 학년과 달리 어휘와 읽기 운율성 요소인 부적절 휴지가 읽기이해를 예측할 수 있는 것으로 나타났다. 논의 및 결론: 학년에 따라 읽기이해를 예측할 수 있는 읽기 유창성 요소가 다른 것으로 나타났다. 이는 학령기 아동의 읽기 유창성 평가 시 자동성 평가뿐 아니라 운율성 평가도 함께 이루어지는 것이 필 요하며 학년에 따라주의 깊게 봐야 할 읽기 유창성 요소가 다름을 시사한다.

핵심어: 읽기 유창성, 자동성, 운율성, 읽기이해

본 연구는 2018년 대한민국 교육부와 한국연구재단의 지원을 받아 수행된 연구임(No. NRF-2018S1A3A2075274).

\section{참고문헌}

김미배, 배소영(2012). 초등 읽기부진 아동의 읽기특성. 언어청각장애연구, 17(4), 565-581.

김서형(2008). 의미 단위 지도를 통한 한국어 읽기 능력 신장 방안. 이중언어학, 38, 69-93.

김소진(2011). 의미단위 띄어 읽기 전략 교수가 읽기이해부진아동의 읽기유창성과 읽기이해에 미치는 영향. 서울교육대학교 대학원 석사학위논문.

김애화, 김의정, 황민아, 유현실(2014). 읽기성취 및 읽기인지처리능력검사(RA-RCP). 서울: 학지사.

김애화, 박성희, 김주현(2010). 초등학생의 읽기유창성 특성 연구: 읽기유창성 발달 패턴 및 오류 유형 분석. 언어청각장애연구, 15(1), 43-55.

김애화, 황민아(2008). 초등학교 고학년의 읽기능력에 영향을 미치는 읽기관련변인에 관한 연구. 언어청각장애연구, 13(1), 1-25.

김영태, 홍경훈, 김경희, 장혜성, 이주연(2009). 수용·표현어휘력검사(REVT). 서울: 서울장애인종합복지관.

배소영, 김미배, 윤효진, 장승민(2015). 한국어 읽기검사(KOLRA). 서울: 학지사.

서민선(2016). 한국어 읽기 유창성 평가 체계화 및 평가 도구 구안 연구. 경인교육대학교 대학원 석사학위논문.

송영복(2012). 음독중심 한국어 수업이 다문화 학습자의 읽기 유창성과 이해도에 미치는 효과. 고려대학교 대학원 박사학위논문.

양병곤(2003). 프라트(Praat)를 이용한 음성분석의 이론과 실제. 부산: 만수출판사.

유남희(2016). 한국어 끊어 읽기 지도 방안 연구: 초등 다문화 배경 학습자를 대상으로. 경인교육대학교 대학원 석사학위논문.

윤효진(2015). 초등 저학년과 고학년의 읽기이해 예측 요인 연구. Communication Sciences \& Disorders, 20(4), 536-546.

윤효진, 배소영, 정부자 (2018). 초등 1-4학년 아동의 읽기이해능력에서 어휘지식의 양과 깊이의 역할. Communication Sciences \& Disorders, 23(2),

519-527.

이윤아, 김정미(2009). RAAC 중재 전략이 지적장애 아동의 읽기유창성과 읽기이해력에 미치는 효과. 특수교육, 8(2), 161-183.

정부자, 김영태, 윤효진(2017). 읽기이해검사의 형식에 따른 관련 요인 탐색. Communication Sciences \& Disorders, 22(1), 66-75.

정성하(2007). 의미단위 끊어 읽기 전략이 초등학교 읽기장애아동의 읽기유창성과 읽기이해력에 미치는 효과. 전남대학교 대학원 석사학위논문.

\section{ORCID}

이지연(제1저자, https://orcid.org/0000-0003-0502-0206); 김영태(교신저자, https://orcid.org/0000-0003-1738-6862);

강진경(공동저자, https://orcid.org/0000-0002-4431-6897) 